удК 343.791

О. А. Соловьева

Санкт-Петербургский государственный университет, г. Санкт-Петербург, Российская Федерация

\title{
ОГРАНИЧЕНИЕ КОНКУРЕНЦИИ (СТ. 178 УК РФ) - МИФ ИЛИ РЕАЛЬНОСТЬ В ПРАКТИКЕ ПРИМЕНЕНИЯ (ТЕОРЕТИЧЕСКИЙ АСПЕКТ)
}

\begin{abstract}
АНнотАция. Данная научная работа посвящена исследованию процесса практики применения и толкования ст. 178 УК РФ «Ограничение конкуренции», в которой автор систематизирует причины «не востребованности» рассматриваемой статьи и определяет основные направления по изменению ее нормативных категорий. В представленной работе автором предлагается разработанный Проект редакции ст. 178 УК РФ под названием «Недобросовестная конкуренция», как один из позиционируемых вариантов толкования, существующих в современном правовом пространстве. Ключевые авторские позиции по модернизации ст. 178 УК РФ заключены в следующем: изменение названия статьи; расширение «сферы влияния» статьи; уточнение «круга лиц, использующих свое служебное положение» . Представленный Проект актуализирован, обоснован и представляет научный интерес для той части юридической общественности, область исследовательских интересов которой лежит в сфере экономических преступлений.

кЛючЕВЫЕ словА. Государственное регулирование; конкуренция; предпринимательство; рыночная экономика; уголовное право; экономические преступления ИНФОРМАЦИЯ О СТАТЬЕ. Дата поступления 26 декабря 2017 г.; дата принятия к печати 19 марта 2018 г.; дата онлайн-размещения 09 апреля 2018 г.
\end{abstract}

O. A. Solovyeva

Saint-Petersburg State University, Saint-Petersburg, Russian Federation

\section{RESTRICTION OF COMPETITION \\ (ART. 178 OF THE CRIMINAL CODE):}

MYTH OR REALITY IN PRACTICAL APPLICATION (THEORETICAL ASPECT)

\begin{abstract}
This scientific work is devoted to studying the process of the practical application and interpretation of Art. 178 of the Criminal Code of the Russian Federation "Restriction of Competition», in which the author systematizes the reasons of «absence of demand" of the article in question and identifies the main directions for changing its normative categories. In the current article the author offers the developed editorial project of Art. 178 of the Criminal Code of the Russian Federation named «Unfair competition», as one of the asserted variants of interpretation existing in the modern legal space. The key author's opinions on modernization of Art. 178 of the Criminal Code are the following: the change of the article's title; the spread of «influence sphere» of the article; the clarification of the "circle of persons using their official position». The presented project is updated, substantiated and it presents a scientific interest for that part of the legal community, whose field of research interests lies in the sphere of economic crimes.
\end{abstract}

KEYWORDS. State regulation; competition; entrepreneurship; market economy; criminal law; economic crimes.

ARTICLE INFO. Received December 26, 2017; accepted March 19, 2018; available online April 09, 2018.

\section{Baikal Research Journal}




\section{Введение}

Процесс становления рыночной экономики в нашей стране, начиная с 1991 года, является приоритетным направлением в деятельности государственных органов власти, в том числе законодательных органов. Согласно Федеральному Закону от 26.07.2006 № 135-ФЗ «О защите конкуренции» (ст. 4 п. «7») ${ }^{1}$, под конкуренцией понимается «соперничество хозяйствующих субъектов, при котором самостоятельными действиями каждого из них исключается или ограничивается возможность каждого из них в одностороннем порядке воздействовать на общие условия [1] обращения товаров на соответствующем товарном рынке». То есть одним из условий эффективного функционирования рынка признается наличие и развитие добросовестной конкуренции, а не ее ограничение.

Данная законодательное декларирование является объективной необходимостью, поскольку ограничение конкуренции может привести к цепочке таких негативных последствий как:

- появление недобросовестной конкуренции [2] в ценовой (тарифной) политике (сговор по повышению и (или) понижению цен (тарифов), установление заранее оговоренных скидок (надбавок, доплат) и (или) наценок, и т.д.);

- появление недобросовестной конкуренции в «поведение на торгах» (например, демпингование цены и т.д.);

- появление недобросовестной конкуренции в регионе (субъекте Российской Федерации) и (или) в стране в целом (сговор в территориальном (сегментарном) делении рынка); и т.д.

Поэтому «Ограничение конкуренции», как деяние, законодателем отнесено, к категории уголовных преступлений в сфере экономической деятельности (УК РФ ст. 178).

Проблема уголовной ответственности за ограничение конкуренции в российской науке уголовного права рассматривается в основном в рамках борьбы с преступлениями в сфере экономической деятельности. Среди российских ученых, которые так или иначе касались в своих научных трудах данной темы исследования следует отметить в частности, работы Б. В. Волженкина, Л. Д. Гаухмана, А. И. Долговой, А. Э. ЗЖалинского, В. Н. Кудрявцева, Н. Ф. Кузнецовой, В. Д. Ларичева, Н. А. Лопашенко, С. В. Максимова, В. И. Тюнина, С. И. Улезько, Т. Д. Устиновой, И. В. Шишко, П. С. Яни и др.

Представленное в литературе многоаспектное рассмотрение изучения проблем уголовной ответственности за ограничение конкуренции, сохраняет научный интерес и актуальность [3] исследования данного вопроса, обусловленное, в первую очередь, действующей редакцией ст. 178 УК РФ

Согласно ст. 178 УК РФ $\Phi^{2}$ экономически активными хозяйствующими субъектами признаются:

- коммерческая и некоммерческая организация;

- индивидуальный предприниматель;

- физическое лицо, незарегистрированные в качестве индивидуального предпринимателя, но осуществляющее профессиональную деятельность, приносящую доход.

Также в ст. 178 УК РФ определены квалифицирующие признаки, определяющие размер уголовной ответственности, а именно:

${ }^{1}$ О защите конкуренции : федер. закон от 26 июля 2006 г. № 135-ФЗ : (ред. от 29 июля 2017). URL: http://www.consultant.ru/document/cons_doc_LAW_61763/ (дата обращения: 09.12.2017).

${ }^{2}$ Уголовный кодек Российской Федераций : федер. закон от 13 июня 1996 г. № 63-ФЗ : (ред. от 29 июля 2017). URL: http://www.consultant.ru/document/cons_doc law 10699/ (дата обращения: 09.12.2017).

\section{Baikal Research Journal}


- ограничение конкуренции, которое произошло в результате деятельности лица, использовавшего свое служебное положение;

- ограничение конкуренции, которое было связано с уничтожением или повреждением чужого имущества, или с угрозой его уничтожения или повреждения;

- ограничение конкуренции, которое причинило особо крупный ущерб (свыше 10000000 Р) или, повлекло извлечение дохода в особо крупном размере (свыше 250000000 Р), наказывается лишением свободы на срок до 6 лет со штрафом в размере до 1000000 P;

- ограничение конкуренции, которое было реализовано с применением насилия или с угрозой его применения, наказывается лишением свободы на срок до 7 лет.

\section{Основная часть}

В связи с постепенным развитием рынка и рыночных отношений в ст. 178 УК РФ многократно вносились существенные изменения в название статьи, ее диспозицию и примечания (Федеральный Закон от 08.12.2003 № 162-ФЗ; Федеральный Закон от 29.07.2009 № 216-ФЗ; Федеральный Закон от 06.12.2011 № 40-ФЗ; Федеральный Закон от 08.03.2015 № 45-ФЗ).

Несмотря на это действующая редакция уголовно-правовой нормы по-прежнему вызывает споры как среди юристов-практиков, так и юристов-ученых [4-6]. Также, как и данные официальной статистики, которые, свидетельствуют о том, что рассматриваемый вид преступления, с одной стороны, не является распространенным, а с другой, свидетельствуют о том, что недостаточная ясность в формулировках приступнообразующих признаков, затрудняет ее применение (рис. 1).

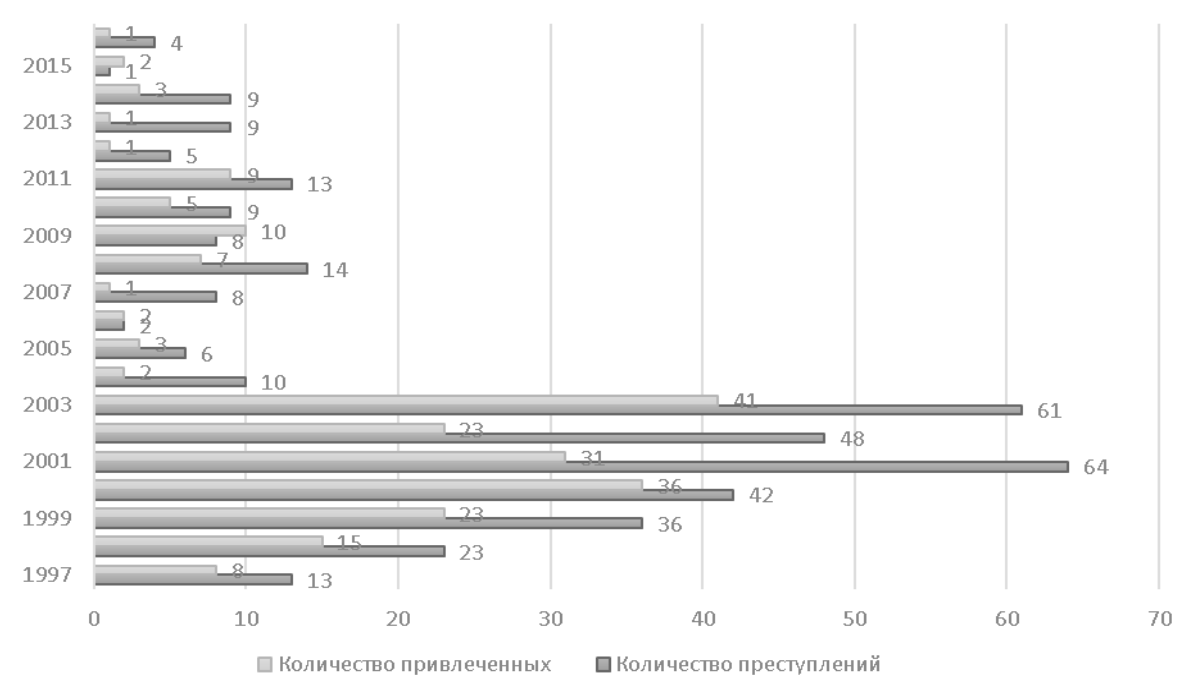

Рис. 1. Количество преступлений и количество привлеченных по ст. 178 УК РФ

Из приеденных данных ${ }^{3}$ видно:

- за период 1997-2016 гг. по ст. 178 УК РФ было выявлено 224 лица и зарегистрировано 385 преступлений;

- за период 1997-2003 гг. по ст. 178 УК РФ наблюдалась положительная динамика как по количеству привлеченных, так и по количеству преступлений по указанной статье;

${ }^{3}$ Судебные и нормативные акты РФ. URL: http://www.sudact.ru (дата обращения: 09.12.2017).

\section{Baikal Research Journal}


- за период 1997-2016 г. по ст. 178 УК РФ отмечается устойчивая тенденция дисбаланса между количеством зарегистрированных преступлений и количеством привлеченных по указанной статье (например, в 2013 г. были привлечены только 11 \%).

Наиболее распространенными [7] причинами «не востребованности» ст. 178 УК РФ являются следующие:

- существует необходимость устанавливать обязательный признак объективной стороны преступления в виде крупного ущерба или дохода в размерах, определенных диспозицией статьи;

- заложена неопределенность в формулировке состава ущерба (причиненного преступлением), заключающаяся в следующем: правомерно или неправомерно учитывать упущенную выгоду (недополученные и неполученные доходы (прибыль)). Данная неопределенность является существенной, поскольку посягательства на экономические интересы хозяйствующих субъектов рынка практически повсеместно сопряжены с упущенной возможностью получения дохода какого-либо размера. При этом отметим сложность в процессе установления размера упущенной выгоды, поскольку разработанная унифицированная методика по данному вопросу, в рамках рассматриваемых уголовных дел, отсутствует;

- сложность в процессе верной квалификации поведения экономически активных хозяйствующих субъектов с точки зрения принадлежности их к картелю (или образования ими картеля). Отметим, что в практике применения Федеральной антимонопольной службой выявляются следующие виды картеля: заключаемые соглашения об ограничении конкуренции с целью вывести в ранг победителя на торгах конкретного хозяйствующего субъекта; заключаемые соглашения об ограничении конкуренции на основе совместной бизнес-деятельности;

- длительность временного периода с момента выявления фактов об ограничении конкуренции до решения органами следствия о возбуждении уголовного дела (или вынесении судебного решения об уголовной ответственности) по выявленным фактам. Данная особенность правоприменения носит негативный характер, поскольку в некоторых случаях к наступлению момента о решении вопроса о возбуждении уголовного дела или вопроса о вынесении судебного решения об уголовной ответственности невозможно объективно и достоверно установить размер ущерба (дохода) в связи со сроком давности.

Поэтому, существует объективная необходимость в модернизации уголовно-правовой нормы, содержащейся в ст. 178 УК РФ.

Систематизируя исследования ученых-юристов, посвященных рассматриваемому вопросу, и авторский взгляд на поставленную проблему исследования, определим следующие основные направления по проектному изменению нормативных категорий, заключенных в ст. 178 УК РФ:

- пересмотреть антимонопольное законодательство РФ [8], в котором изложена сама Концепция антимонопольной политики и основные категории, применяемые при вынесении судебного решения. В частности, предлагается установить ответственность для экономически активных хозяйствующих субъектов [9] за попытку достичь доминирующего положения на рынке незаконными методами конкурентной борьбы (описываемое деяние характеризуется юридической категорией «недобросовестная конкуренция», понятие о которой закреплены в ст. 34 п. 2 Конституции РФ ${ }^{4}$ и ст. 4, ст. 14 Федерального Закона от 26.07.2006 № 135Ф3 «О защите конкуренции»);

- расширить круг экономически активных хозяйствующих субъектов, к деятельности которых целесообразно применение ст. 178 УК РФ. В частности,

4 Конституция Российской Федерации. URL: http://www.constitution.ru/ (дата обращения: 09.12.2017).

\section{Baikal Research Journal}

электронный научный журнал Байкальского государственного университета 
предлагается предусмотреть ответственность за совершение деяния не только для субъектов, монополизировавших рынок, но и для лиц, чьи экономические интересы частично и (или) полноценно представлены в двух и более экономически активных хозяйствующих субъектах в рамках одного сегмента рынка;

- уточнить квалификации совместной деятельности субъектов хозяйствования. В частности, предлагается совместные действия экономически активных хозяйствующих субъектов, направленные на монополизацию рынка, квалифицировать как действия, совершенные группой лиц (или организованной группой) по предварительному сговору.

На основании выше изложенного автором предлагается следующая редакция ст. 178 УК РФ.

\section{Проект статьи 178 УК РФ «Недобросовестная конкуренция»}

1. Проявление недобросовестной конкуренции путем заключения между хозяйствующими субъектами, то есть физическими и (или) юридическими лицами (в том числе субъектами-конкурентами) любого соглашения с целью монополизации определенного сегмента рынка и (или) территориальной части административно-территориального образования, запрещается, если это деяние причинило крупный ущерб гражданам, организациям или государству либо повлекло извлечение дохода в крупном размере, - наказываются штрафом в десятикратном размере причиненного ущерба или в десятикратном размере заработной платы или иного дохода осужденного за период от одного года до двух лет, либо принудительными работами на срок до трех лет с лишением права занимать определенные должности или заниматься определенной деятельностью на срок до трех лет или без такового, либо лишением свободы на срок до трех лет с лишением права занимать определенные должности или заниматься определенной деятельностью на срок до трех лет либо без такового.

2. Те же деяния:

а) совершенные лицом с использованием своего служебного положения, в рамках исполнения своих профессиональных обязанностей на должности государственной службы или иной должности не относящейся к таковой;

б) сопряженные с уничтожением или повреждением чужого имущества либо с угрозой его уничтожения или повреждения, при отсутствии или присутствии признаков вымогательства;

в) причинившие особо крупный ущерб либо повлекшие извлечение дохода в особо крупном размере, - наказываются принудительными работами на срок до пяти лет с лишением права занимать определенные должности или заниматься определенной деятельностью на срок до трех лет или без такового либо лишением свободы на срок до шести лет со штрафом в размере до одного миллиона рублей или в десятикратном размере заработной платы или иного дохода осужденного за период до пяти лет или без такового и с лишением права занимать определенные должности или заниматься определенной деятельностью на срок до трех лет или без такового.

3. Деяния, предусмотренные частями первой или второй настоящей статьи, совершенные с применением насилия или с угрозой его применения, - наказываются принудительными работами на срок до пяти лет с лишением права занимать определенные должности или заниматься определенной деятельностью на срок до пяти лет либо лишением свободы на срок до семи лет с лишением права занимать определенные должности или заниматься определенной деятельностью на срок до пяти лет.

Отметим ключевые позиции в Проекте по модернизации ст. 178 УК РФ:

\section{Baikal Research Journal}

электронный научный журнал Байкальского государственного университета 
1. Изменение названия статьи.

Как упоминалось выше, неоднородность категориального аппарата в сопоставлении Федеральных Законов (рассматривающих экономические правонарушения, регламентирующих хозяйственную деятельность, регулирующих поведение хозяйствующих субъектов на рынке и т.д.) с Уголовным Кодексом Российской Федерации дает возможность избежания уголовной ответственности (уголовного наказания). В связи с этим, автор полагает, что необходимо использовать конвергентный подход, синергию при формулировании основных категорий в Главе 22 УК РФ (в том числе в ст. 178 УК РФ). Поэтому руководствуясь ст. 34 п. 2 Конституции РФ и ст. 4, ст. 14 Федерального Закона от 26.07.2006 № 135-Ф3 «О защите конкуренции», автор предлагает название ст. 178 УК РФ «Ограничение конкуренции» заменить на «Недобросовестная конкуренция» .

2. Расширение «сферы влияния» статьи.

В Проекте ст. 178 УК РФ п. 1 автор предлагает акцентировать внимание на следующих категориях, которые никогда ранее не фигурировали в той или иной трактовке рассматриваемой статьи:

- субъекты-конкуренты (поскольку конкуренты, если даже они функционируют не в рамках одного сегмента рынка (понятие смежного производства) могут вступать в краткосрочные или среднесрочные сговоры с целью максимизации своей прибыли и (или) устранения конкурентов (развивающихся на рынке субъектов хозяйствования));

- монополизация территориальной части административно-территориального образования (поскольку категория «монополизация рынка» в условиях цифровой экономики применима к конкретной территории, имеющей административные границы, например, часть или полностью район городского округа, поселения, деревни и т.д.).

3. Уточнение «круга лиц, использующих свое служебное положение».

Автор предлагает в ст. 178 п. 2 («а») конкретизировать, что в качестве ответственных за совершенное деяние (повлекшее возникновение недобросовестной конкуренции) привлекаются не только государственные служащие, но и лица, занимающие иные административные должности, не относящиеся к понятию «государственной службы». Данное правовое уточнение расширит практику применения указанной статьи и позволит более точно квалифицировать совершаемые деяния в рамках формирования условий для недобросовестной конкуренции.

Заключение

Как показывает анализ [10] судебных решений за 2017 год, ст. 178 УК РФ лишь несколько раз фигурировала в процессе рассмотрения дел ${ }^{5}$, а именно:

- в делах, где по решению Суда не было выявлено состава преступления по ст. 178 УК РФ (Прилузский районный суд (Республика Коми) Решение от 23.06.2017 г. по Делу № 2-252/2017; Арбитражный суд г. Москвы Решение от 05.07.2017 г. по Делу № А40-196848/2016; Прилузский районный суд (Республика Коми) Решение от 07.07.2017 г. по Делу № 2-267/17);

- в деле, где была допущена техническая ошибка (опечатка - вместо ст. 158 УК РФ, была указана ст. 178 УК РФ - Кемеровский областной суд (Кемеровская область) Апелляционное постановление от 06.07.2017 г. по Делу № 22-2907/2017).

На основании выше изложенного, отметим следующее, что на сегодняшний момент остаются сложности в трактовке и применении ст. 178 УК РФ. Это вызвано радом причин, в том числе частичным расхождением и использованием

${ }^{5}$ Государственная автоматизированная система Российской Федерации «Правосудие» : интернет-портал. URL: http://www.sudrf.ru (дата обращения: 09.12.2017).

\section{Baikal Research Journal}

электронный научный журнал Байкальского государственного университета 
категориального аппарата в нормативно-правовых актах, регулирующих и не допускающих монополистический вид деятельности на рынке.

Отметим и то, что после 2010 года [11] Уголовный Кодекс Российской Федерации (Глава 22 «Преступления в сфере экономической деятельности») «взял курс» на либерализацию уголовной ответственности. Это было обусловлено принятием Федерального Закона от 07.04.2010 г. № 60-ФЗ «О внесении изменений в отдельные законодательные акты Российской Федерации» ${ }^{6}$, в рамках которого законодателем накладывался запрет на помещение под стражу предпринимателей, совершивших преступления в экономической сфере.

Реализация принципа гуманизма в законодательстве [12], в отношении бизнесменов (у которых появилась возможность ожидания судебного приговора на свободе), обосновывается общим понятием «презумпции невиновности» (например, ст. 49 Конституции РФ, ст. 14 УПК РФ 7 , ст. 1.5 КоАП РФ 8 ) и отсутствием, например, угрозы для жизни, здоровья кого-либо. Тем не менее, за судебной инстанцией по-прежнему сохранилось право о принятие решения о месте пребывания предпринимателя (в отношении которого рассматривается Дело), поскольку именно Суд учитывает состав преступления, личность обвиняемого, его взаимодействие со следственными органами и т.д.

В уголовно-правовой политике, направление «либерального гуманизма», в отношении предпринимательской и иного вида экономической деятельности, реализуется по настоящее время. Об этом свидетельствует, в том числе, Постановление № 48 от 15.11.2016 г. Пленума Верховного Суда РФ «О практике применения судами законодательства, регламентирующего особенности уголовной ответственности за преступления в сфере предпринимательской и иной экономической деятельности» ${ }^{9}$. В преамбуле Постановления указано:

- о необходимости ограждения бизнесменов от необоснованного уголовного преследования;

- о недопустимости использования уголовного наказания в качестве инструмента, оказывающего давление на предпринимателей;

- о невозможности применения уголовного преследования в качестве способа разрешения каких-либо споров между экономически активными хозяйствующими субъектами.

Таким образом, в ныне существующей уголовно-правовой законодательной системе произошла легитимезация дополнительных правовых гарантий обеспечения прав бизнесменов, привлекаемых к уголовной ответственности за определенные экономические преступления. Поэтому модернизация ст. 178 УК РФ является своевременной и актуальной.

\section{Список использованной литературы}

1. Баранов В. М. Классификация в Российском законодательстве: (теоретико-прикладное исследование) : монография / В. М. Баранов, А. П. Кузнецов, Н. Н. Маршакова. - М. : Юрлитинформ, 2014. - 160 с.

${ }^{6}$ О внесении изменений в отдельные законодательные акты Российской Федерации : федер. закон от 07 апр. 2010 г. № 60-ФЗ : (ред. от 03.07.2016). URL: http://www.consultant.ru/document/ cons_doc_LAW_99174/ (дата обращения: 09.12.2017).

7 Уголовно-процессуальный кодекс Российской Федерации : федер. закон от 18 дек. 2001 г. № 174-ФЗ : (ред. от 29 июля 2017 г., с изм. от 14 нояб. 2017). URL: http://www.consultant.ru/ document/cons doc LAW 34481/ (дата обращения: 09.12.2017).

${ }^{8}$ Кодекс Российской Федерации об административных правонарушениях : федер. закон от 30 дек. 2001 г. № 195-ФЗ : (ред. от 27 нояб. 2017, с изм. от 04 дек. 2017). URL: http://www.consultant.ru/ document/cons_doc_LAW_34661/(дата обращения: 09.12.2017).

9 Российская газета. 2016. 24 нояб. URL: http://www.rg.ru/2016/11/24/postanovlenie-vs-dok. html (дата обращения: 09.12.2017).

\section{Baikal Research Journal}


2. Лопашенко Н. А. Преступления в сфере экономической деятельности: теоретический и прикладной анализ : монография : [в 2 ч.] / Н. А. Лопашенко. - М. : Юрлитинформ, 2015. - Ч. 1. - 336 с.

3. Актуальные проблемы уголовного права : монография / А. П. Кузнецов [и др.]. Н. Новгород : Изд-во Нижегор. акад. МВД России, 2014. - 174 с.

4. Леонтьев Б. М. Преступления в сфере экономической деятельности / Б. М. Леонтьев, Н. Е. Крылова. - М. : Зерцало-М, 2012. - 264 с.

5. Русанов Г. А. Экономические преступления / Г. А. Русанов. - М. : Юрайт, 2017. $224 \mathrm{c}$.

6. Бертовский Л. В. Расследование преступлений экономической направленности / Л. В. Бертовский. - М. : Проспект, 2017. - 310 с.

7. Куринов Б. А. Научные основы квалификации преступлений / Б. А. Куринов. М. : Изд-во МГУ, 1984. - 181 с.

8. Основные проблемы реформирования уголовно-правовых норм об экономических преступлениях и практика их применения на современном этапе развития России / Л. Л. Кругликов [и др.]. - Ярославль : ЯрГУ, 2012. - 369 с.

9. Преступность, национальная безопасность, бизнес / под общ. ред. А. И. Долговой. М. : Российская криминологическая ассоциация, 2012. - 650 с.

10. Яни П. С. Проблемы уголовно-правовой охраны экономики от недобросовестной конкуренции / П. С. Яни // Российская юстиция. -2010. - № 11. - С. 22-26.

11. Тюнин В. И. Юридическая конструкция деяний в сфере экономической деятельности и решение спорных вопросов конкуренции и совокупности уголовно-правовых норм / В. И. Тюнин. - СПб. : СПб ун-т МВД РФ, 2001. - 190 с.

12. Бацин И. В. Институт конкурентных отношений в системе уголовно-правовой охраны главы 22 УК РФ / И. В. Бацин // Юридическая наука и практика: Вестник Нижегородской академии МВД России. - 2014. - № 3 (27). - С. 184-190.

\section{References}

1. Baranov V. M., Kuznetsov A. P., Marshakova N. N. Klassifikatsiya v Rossiiskom zakonodatel'stve: (teoretiko-prikladnoe issledovanie) [Classification in the Russian legislation: (theoretical and applied research)]. Moscow, Yurlitinform Publ., 2014. $160 \mathrm{p}$.

2. Lopashenko N. A. Prestupleniya $v$ sfere ekonomicheskoi deyatel'nosti: teoreticheskii $i$ prikladnoi analiz [Crimes in the sphere of economic activity: theoretical and applied analysis]. Moscow, Yurlitinform Publ., 2015, vol. 1. 336 p.

3. Kuznetsov A. P., Pronina M. P., Sizova V. N., Stepanov M. V. Aktual'nye problemy ugolovnogo prava [Topical problems of criminal law: Monograph]. Nizhny Novgorod Academy of the Ministry of Internal Affairs of the Russian Federation Publ., 2014. 174 p.

4. Leont'ev B. M., Krylova N. E. Prestupleniya $v$ sfere ekonomicheskoi deyatel'nosti [Crimes in the sphere of economic activity]. Moscow, Zertsalo-M Publ., 2012. 264 p.

5. Rusanov G. A. Ekonomicheskie prestupleniya [Economic Crimes]. Moscow, Yurait Publ., 2017. 224 p.

6. Bertovskii L. V. Rassledovanie prestuplenii ekonomicheskoi napravlennosti [Investigation of economic crimes]. Moscow, Prospekt Publ., 2017. 310 p.

7. Kurinov B. A. Nauchnye osnovy kvalifikatsii prestuplenii [Scientific bases of crime qualification]. Lomonosov Moscow State University Publ., 1984. 181 p.

8. Kruglikov L. L., Ivanchin A. V., Komarova O. Yu., Kuznetsov A. P. Osnovnye problemy reformirovaniya ugolovno-pravovykh norm ob ekonomicheskikh prestupleniyakh i praktika ikh primeneniya na sovremennom etape razvitiya Rossii [Main problems of reforming criminal law norms on economic crimes and practice of their application at the present stage of Russia's development]. Yaroslavl State University Publ., 2012. 369 p.

9. Dolgova A. I. (ed.). Prestupnost', natsional'naya bezopasnost', biznes [Crime, National Security, Business]. Moscow, Rossiiskaya kriminologicheskaya assotsiatsiya Publ., 2012. 650 p.

10. Yani P. S. Problems of criminal legal protection of economy against unfair competition. Rossiiskaya yustitsiya = Russian Justice, 2010, no. 11, pp. 22-26. (In Russian).

11. Tyunin V. I. Yuridicheskaya konstruktsiya deyanii v sfere ekonomicheskoi deyatel'nosti $i$ reshenie spornykh voprosov konkurentsii $i$ sovokupnosti ugolovno-pravovykh norm [Legal construction of acts in the field of economic activity and solution of contentious issues of compe-

\section{Baikal Research Journal}


tition and set of criminal law norms]. Saint Petersburg University of the Ministry of Internal Affairs of the Russian Federation., 2001. $190 \mathrm{c}$.

12. Bacin. I. V. Institute of competitive relations in the system of the criminal-law protection of chapter 22 of the Criminal code of the Russian Federation. Yuridicheskaya nauka i praktika: Vestnik Nizhegorodskoi akademii MVD Rossii = Legal science and practical: Journal of Nizhniy Novgorod Academy of the Ministry of the Interior of the Russian Federation, 2014, no. 3 (27), pp. 184-190. (In Russian).

\section{Информация об авторе}

Соловьева Олеся Анатольевна - кандидат экономических наук, магистр юриспруденции, доцент, кафедра экономической теории и социальной политики, Санкт-Петербургский государственный университет, 199034, г. Санкт-Петербург, Университетская наб., 7/9, e-mail: olesia-la-la@list.ru.

\section{Author}

Olesya A. Solovyeva - PhD in Economics, Master Degree in Jurisprudence, Associate Professor, Chair of Economic Theory and Social Policy, St. Petersburg State University, 7/9 Universitetskaya nab., 199034, St. Petersburg, e-mail: olesia-la-la@list.ru.

\section{Для цитирования}

Соловьева О. А. Ограничение конкуренции (ст. 178 УК РФ) - миф или реальность в практике применения (теоретический аспект) / О. А. Соловьева // Baikal Research Journal. - 2018. - T. 9, № 1. - DOI : 10.17150/2411-6262.2018.9(1).18.

\section{For Citation}

Solovyeva O. A. Restriction of Competition (Art. 178 of the Criminal Code): Myth or Reality in Practical Application (Theoretical Aspect). Baikal Research Journal, 2018, vol. 9, no. 1. DOI: 10.17150/2411-6262.2018.9(1).18. (In Russian).

\section{Baikal Research Journal}

